Proceedings of the 2012 Winter Simulation Conference

C. Laroque, J. Himmelspach, R. Pasupathy, O. Rose, and A.M. Uhrmacher, eds

\title{
EXCHANGE RATES AND TRADE TARIFFS ASSESSMENT FOR STRATEGIC DECISIONS IN SUPPLY NETWORKS CONFIGURATION
}

\author{
Eduardo Saiz \\ Jone Uribetxebarria \\ IK4-IKERLAN Research Alliance \\ $\mathrm{P}^{\mathrm{o}} \mathrm{J} . \mathrm{M}^{\mathrm{a}}$. Arizmendiarrieta, 2 \\ Arrasate-Mondragón, 20500, SPAIN
}

\begin{abstract}
This paper seeks to address the strategic design of suitable supply network configurations in response to market fluctuations in exchange rates and trade tariffs that may take place in international trade scenarios. Using a simulation model and experimental design methods, the impact that both variables have on the profitability of the products supplied to the market is analyzed. Different configurations of a supply network belonging to a world leader manufacturer of components for the appliances sector are considered. Each configuration is evaluated by simulation from a set of economic scenarios resulting from combinations of exchange rates and trade tariffs values belonging to the countries involved in the supply network. As a result of the study, the effect of each variable on the product margin is presented and some decision criteria are introduced allowing the company to adapt quickly and efficiently its supply network to each specific situation of the market.
\end{abstract}

\section{INTRODUCTION}

In the current context of economic crisis, globalization and transformation of production patterns, funding constraints together with an uncertain and falling demand have become in threats which severely affect the future of businesses. Other issues such as shortages and high prices of raw materials, increased transport costs or the advent of emerging countries are increasing the complexity of today's competitive scenario.

In this sense, the design of flexible and efficient supply networks that can quickly adapt to the competitive requirements of this new scenario plays a critical role in the survival of companies. The increasing complexity of supply networks, especially those owned by firms to compete globally, suggest the need of introducing new procedures and management tools for business analysis in order to increase the accuracy and robustness of decisions related to the supply network configuration. The highly strategic and economic relevance of this kind of decisions call for having a comprehensive and accurate information to reduce the risk and time involved in making decisions and their subsequent deployment in the organization.

Some of the most common problems involved in designing a supply network are related to decisions about the number and location of production and storage facilities, their allocation according to the products supplied to each market region or the selection and allocation of raw material, components and subassemblies suppliers (Chopra and Meindl 2004). When extending the design to supply networks operating globally, new factors such as the international location of facilities and subsidies given by governments for its implantation, differences in labor costs, socio-economic risks and specific regulations of each country or international trade concerns must be considered (Ferdows 1997). Other aspects such as the 


\section{Saiz and Uribetxebarria}

proximity of the firm to customers or the presence of reliable suppliers are key issues in the supply network design decisions (MacCormack et al. 1994).

Regarding international trade, volatility and uncertainty of the global economy makes some factors such as currency exchange rates or the presence of tariffs and customs duties in different countries where a company operates have a significant role in the supply network design. These factors directly affect the price to be paid for goods supplied and can generate significant fluctuations in the economic viability of the supply network. According to Meixell and Gargeya (2005), this problem has been investigated continuously for the last two decades complementing the research work done until early 1990 in which tariffs and customs duties were predominant factors. As a result, the research community has developed numerous models of global supply networks in which these factors are taken into account.

One group of these models use different optimization methods for finding specific solutions to problems related to the design of a supply network such as the optimal location of production facilities (Canel and Khumawala 1996, Lowe et al . 2002), the transfer of production between different plants of the supply network (Haug 1992), the total profit maximization of the supply network (Cohen and Lee 1989) or the comparison between transportation alternatives and inventory costs (Vidal and Goetschalckx 2001).

A second group use simulation techniques to support the strategic decision making related to the supply network design. According to Chang and Makatsoris (2001), simulation models allow what-if analysis comparing different alternatives in a relatively short time without interfering with the real system. For this reason, the use of simulation models for designing supply networks is a valuable analysis tool to make correct decisions in one of the most important areas for the survival of the company (IMTI 2000). In the literature are present multiple examples of simulation models that address strategic decisions relating to the configuration and location of the different supply network nodes (Bagchi et al. 1998, Zhang et al. 1998, Siprelle et al. 1999, Petrovic 2001, Phelps et al. 2001, Ritchie et al. 2003).

As well as the fluctuations of currency exchange rates and tariffs are usually included in optimization models for the design of a supply network (Meixell and Gargeya 2005), there are not too many references to their processing with simulation models. The work presented aims to contribute to cover this gap proposing a simulation model to analyze the influence of both factors on the configuration of a supply network.

The research was conducted using a case study of a Spanish world leader company that manufactures components for the domestic appliances sector. Section 3 presents the characteristics of the two supply network configurations that the company has to supply valves for gas ovens to the assembly plants that its customers have in Brazil. Next, section 4 shows the main features of the simulation model and the technologies employed: discrete event and multi-agent simulation. Section 5 describes the details of experimentation and the results obtained. For each of the supply network configurations it has been simulated a set of experiments varying the values of the input variables: exchange rates between currencies (Euro/Real, Euro/Yuan, Real/Yuan) and input tariffs in Brazil for components and finished products. Comparing individual and combined effects of these variables on the product margin, Section 6 draws conclusions and performance criteria for the company.

\section{RESEARCH APPROACH}

The research has been developed based on: (1) Previous studies identified in the literature; (2) A case study research of a large manufacturer of components for the domestic appliances sector with a global multi-plant network and requirements for speed and flexibility in strategic decisions related to its supply network configuration; (3) A simulation environment for modeling the supply network in order to generate the required data to be analyzed; (4) Experimental design methods for analyzing the data collected from the simulations.

Taking into account the four aspects mentioned above, the study has been carried out using the following steps:

1. Detailed study of the business case collecting all relevant information regarding the product, process and supply network of the company. 
2. Simulation model development including the supply network modeling as well as the calibration and validation of the model.

3. Design of simulation experiments identifying the main input-output variables to be analyzed and the strategy that is going to perform each simulation experiment (ranges and increments of input variables, presentation of results, etc.).

4. Simulation experiments run.

5. Collection and analysis of results using experimental design methods.

The research method chosen was selected because of its closeness and applicability to the reality of the company. Case studies are frequently used for exploratory and theory building research (Yin 1994) and the combination of simulations models with different experimental design methods has been widely discussed by different authors (Swain and Farrington 1994, Kleijnen 1998, Kelton 1999, Kelton 2000).

\section{CASE STUDY DESCRIPTION}

\subsection{Company and Market}

The case study corresponds to a Spanish company that develops and manufactures components for the domestic appliances sector since 1963. During 2010, the Group's consolidated turnover amounted to 221 million Euros, with a workforce of more than 1,500 people and with eight production plants in Europe, Asia and America, which positions it as one of the worldwide leaders in this sector.

Company's market is characterized by a growing tendency to the presence of more concentrated and globalized customers, in this case manufacturers of domestic appliances, with large purchasing volumes and pressure on costs strategies. These customers are introducing new production plants specialized by product, locating them in those parts of the world, mainly in low cost countries (LCC) of Eastern Europe and Asia, which are more attractive for existing market growth in these regions as well as by the low cost of labor and local suppliers.

The company's expansion has been carried out following the strategy marked by their customers having to internationalize their activities to provide a local and customized service where the customer is implanted. This competitive strategy has resulted in a great complexity of the supply network of the company that must have a global presence, with facilities in different countries, providing a wide range of products adapted to the particular requirements of their customers and with a global network of suppliers to be properly managed in order to achieve service levels and costs demanded for its customers. This complexity has been increased by the growing significance of factors such as fluctuations in the prices of raw materials, transport costs and currency exchange rates as well as the introduction of changes in interest rates or tariff regulations of each country complicating the management of the supply network.

\subsection{Product and Process Characteristics}

The product that has been selected for the case of study is a valve for gas ovens that are consumed in the Brazilian market. Figure 1 shows a diagram with the list of components that make up the valve. 


\section{Saiz and Uribetxebarria}

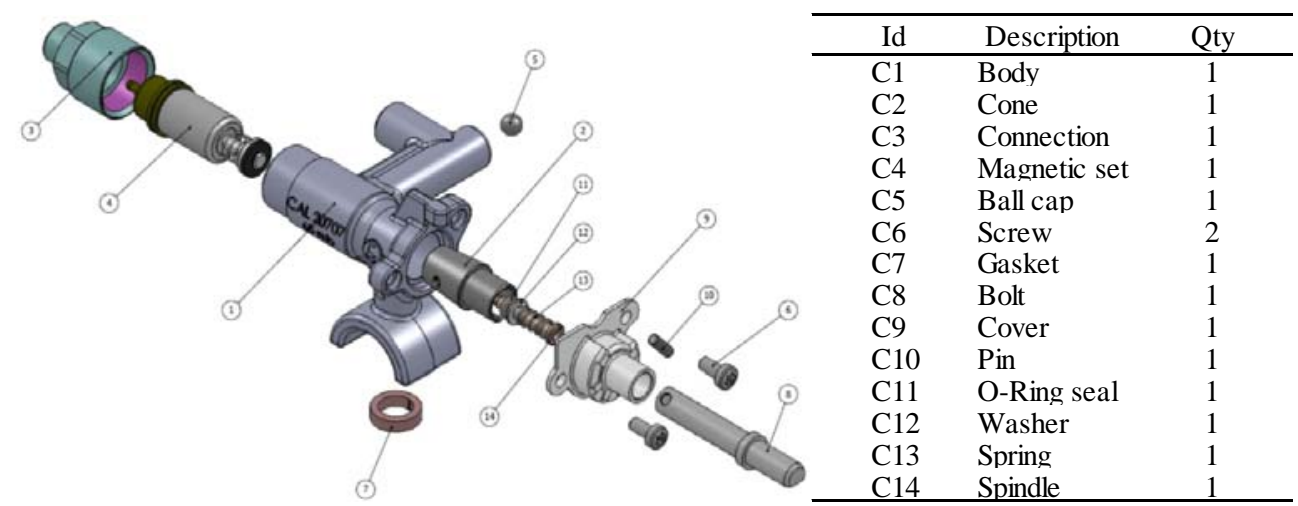

Figure 1: Breakdown drawing of the valve for gas ovens.

The gas valve is a simple product that has a single level of structure in which all components are unitary except the two screws. Components provided by different suppliers are assembled in specialized assembly lines, with a high level of automation and very low processing times.

\subsection{Supply Network Configurations}

The selected valve is supplied to domestic appliance manufacturers operating in the Brazilian market according to the specifications and regulations in the country. To accomplish the supply of valves, the company considers two configuration alternatives of its supply network:

- Configuration 1: We see in Figure 2 that the valve assembly takes place in the Brazilian assembly plant of the company from which the finished product is served to customers.

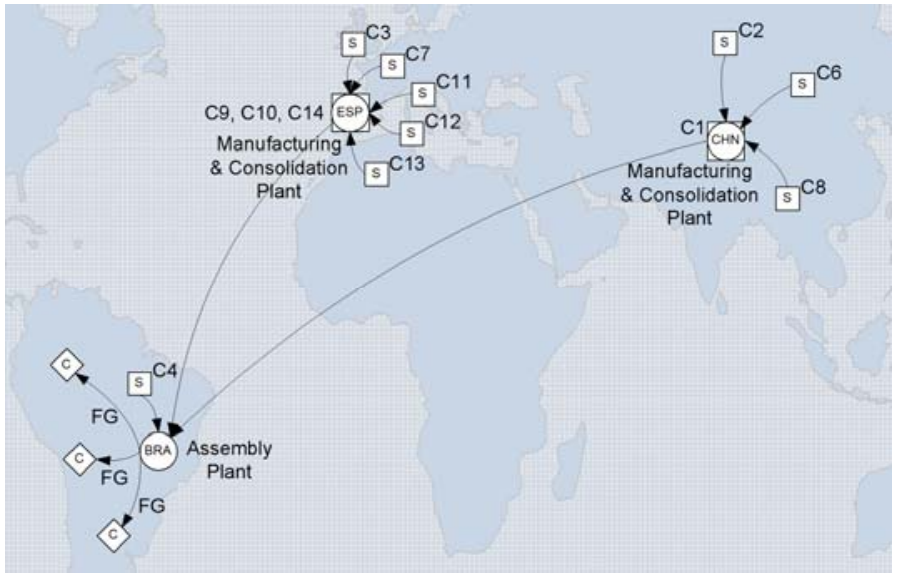

Figure 2: Supply Network configuration 1.

In this configuration, the assembly plant of Brazil receives components from Brazilian suppliers and from plants that the company has in Spain and China. These two plants, in addition to manufacturing some components themselves, C9, C10 and C14 in the case of Spain and C1 in China, act as consolidation centers for European and Asian suppliers of the rest of components seeking to reduce shipping costs to Brazil.

- Configuration 2: The valve assembly is made at its plant of China, sending the finished product to the plant in Brazil where it is stored for later distribution to customers (see Figure 3). This alternative arises due to the fact that the plant in China is specialized in the manufacture of bodies and cones as well as the assembly of other valves for the Asian market. 


\section{Saiz and Uribetxebarria}

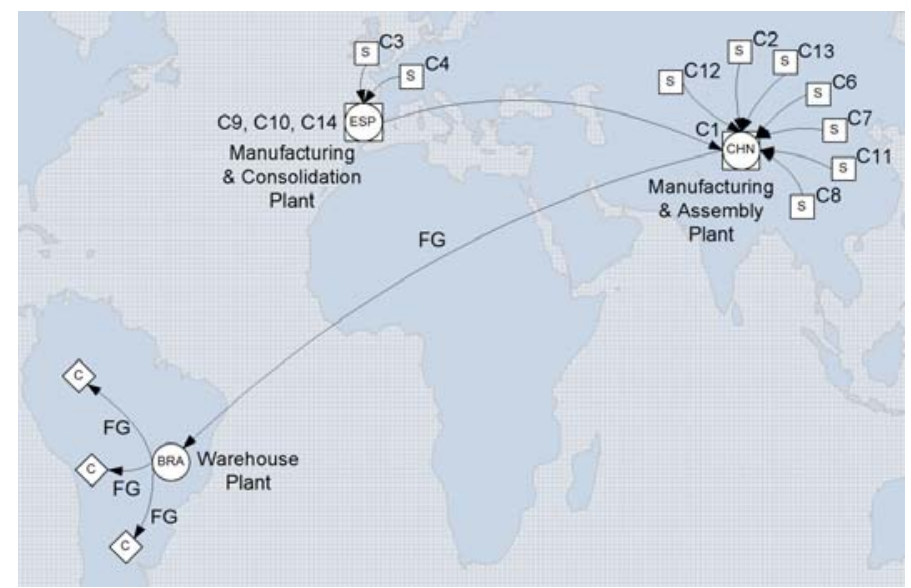

Figure 3: Supply Network configuration 2.

In this supply network configuration, the Spanish plant supplies to the plant in China components manufactured by itself (C9, C10 and C14) and consolidated from European suppliers (C3 and C4). This alternative requires a change of the Brazilian supplier of component C4 by an European supplier. Likewise, there are new Asian suppliers instead of European for components C7, C11, C12 and C13.

\subsection{Research Problem}

The company considers the possibility of using both alternatives to supply the product to the Brazilian market. To facilitate decision-making needs to have additional information about the potential impact on business profitability the economic fluctuations that can occur when a company operates globally.

In particular, the company wants to know, for both supply network configurations, the impact on the product margin of the following factors:

- Fluctuation in currency exchange rate between the different countries involved in the supply of valves (Euro (EUR) / U.S. Dollar (USD) / Brazilian Real (BRL) / Chinese Yuan Renminbi (CNY)).

- Changes of tariff policies for imports of components and finished products to Brazil and China.

On the basis of a predefined scenario of demand according to the supply contracts that the company has agreed with their customers, a set of fluctuating scenarios for both factors will be analyzed to obtain conclusions and performance criteria possible allowing company decision makers to act more quickly and accurately.

\section{SIMULATION MODEL DESCRIPTION}

The simulation model for the case study is built by customizing a generic simulator developed previously (Saiz et al. 2006). This simulator allows us to analyze the performance of a supply network as a result of the introduction of changes in demand, network topology, product and operations structures and inventory allocation, among others.

The construction of the simulator is started with the creation of the network topology that consists of "nodes" and "arcs". The nodes correspond to points of the supply network where activities occur: suppliers, manufacturing facilities and warehouses. The nodes are connected by arcs, through which information and materials flows takes place.

As we can see in Figure 4, the simulation model uses an architecture based on the collaboration of agents that interact according to a defined set of rules and generate the system's behavior. 


\section{Saiz and Uribetxebarria}

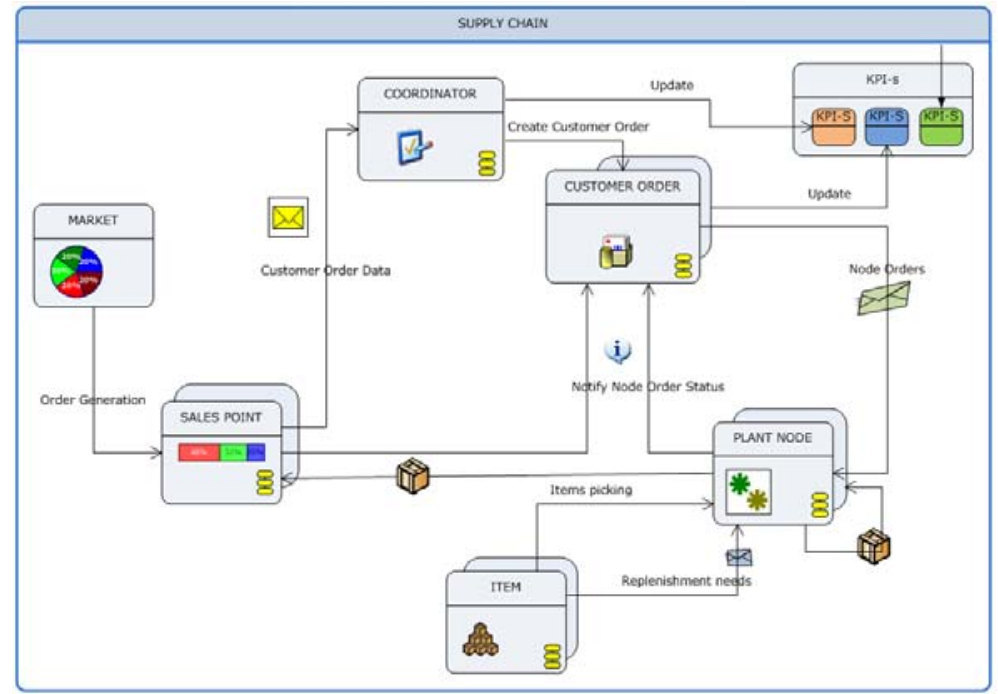

Figure 4: Agents collaboration chart.

The supply network management is centralized highlighting the role played by the so-called "Coordinator Agent" which has a global overview of the supply network deciding when and how it will be provided each customer order and supervising its execution from order arrival to delivery. Furthermore, this agent is responsible for updating the values of a set of KPIs: delivery time, assets utilization, inventory levels, product margins and different kind of costs (production, storage, freight, tariffs, etc.), that have been established to shows the results of simulations.

In addition to the Coordinator Agent, the simulation model has other agents that play different roles:

- "Supply Chain Agent" is the main agent that contains all the other network agents. These agents collaborate to enable the supply network to execute the process from receipt of a customer order until the customized product is delivered to the customer. This agent creates the network of agents and registers the performance indicators in a KPI structure.

- "Market Agent" contains the operating rules established for each market region, customer type and sales percentage according to product requirements. In this way, this agent characterizes the generation of customer orders.

- "Sales Point Agent" is the place at which customer orders are created in accordance with the rules defined with the market agent.

- Set of "Plant Nodes Agents" which make up the production nodes (suppliers, manufacturers, warehouses) that build the product from customer orders. The "Coordinator Agent" decides which plant nodes will be involved in each customer order execution establishing the corresponding instance of supply network for each one.

- “Customer Order Agent" is an internal agent of the coordinator agent which executes and supervises each customer order in accordance with the network instance selected by the coordinator agent to make each supply.

- Set of "Items Agents" to simulate the behavior of materials that make up the product with regard to replenishment strategies.

The set of activities performed by these agents is modeled based on discrete events using state diagrams (SD). Figure 5 shows the schema with the existing relationships between three agents of the simulation model and their corresponding SD. 


\section{Saiz and Uribetxebarria}

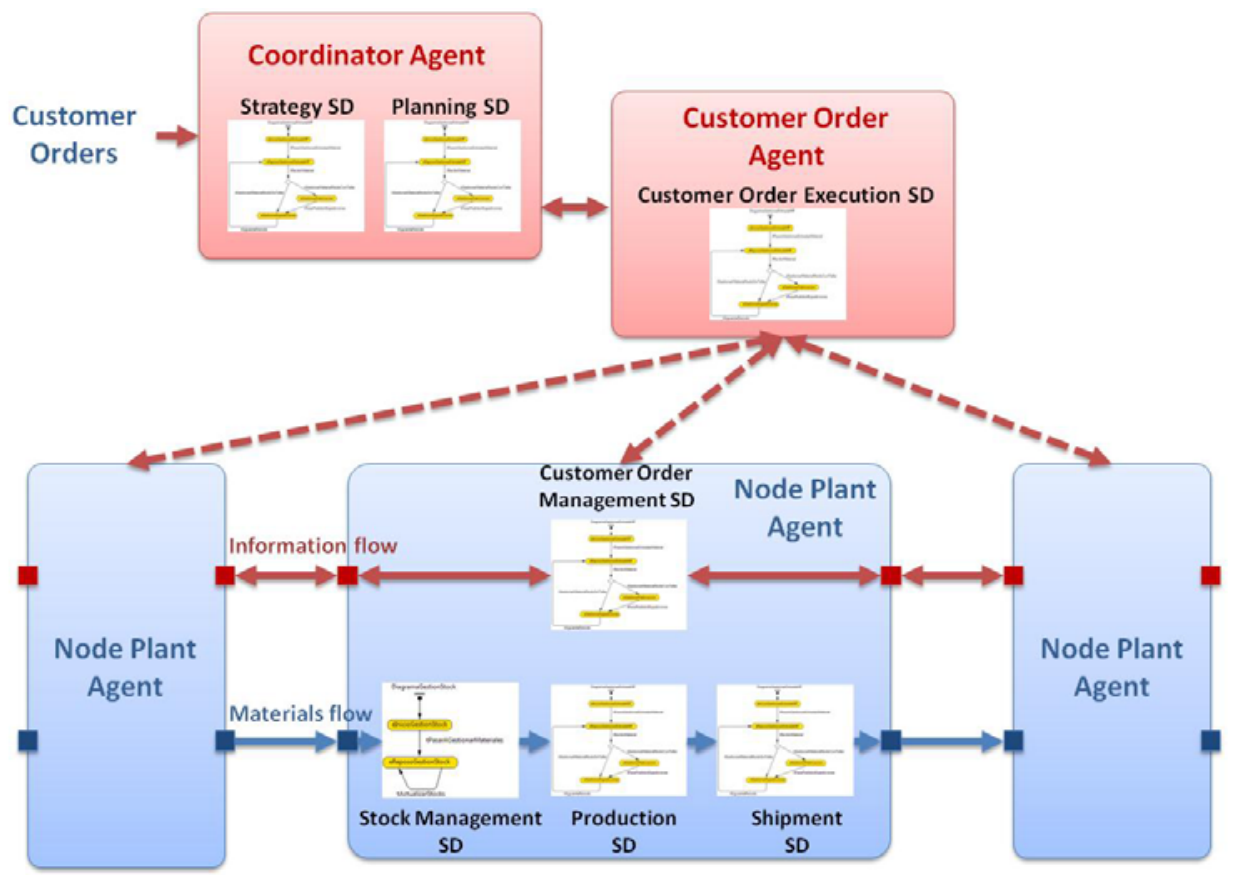

Figure 5: Simulation model agents and state diagrams scheme.

SD functionality belonging to each of the three referred agents is the following:

- "Coordinator Agent" has two major state diagrams: (i) Strategy SD which processes customer orders received and determines the strategy for managing these orders selecting the optimum market strategy, analyzing all the network alternatives and deciding which one best suits customer and company needs; and (ii) Planning SD which periodically plans and releases customers orders taking into account available capacity and delivery times of the supply network.

- “Customer Order Agent" has associated another state diagram called Customer Order Execution $S D$ that generates all the supply network orders required for providing the items that are needed to fulfil the final customer order. It also performs regular follow-up of the customer order execution.

- "Plan Node Agent" has four state diagrams to manage raw materials and components from their procurement receipt until end product delivery: (i) Customer Order Management SD which, taking into account the selected manufacturing strategy (Make-To-Stock, Make-To-Order, Assembly-To-Order), places orders in queues for its manufacturing or queues for supplying end products from warehouses; (ii) Production SD which manages orders execution in the transformation workshop; (iii) Shipment $S D$ that manages conditions for end products shipping; and (iv) Stock Management $S D$ which manages materials inventory levels in warehouses.

As a result of the agents collaboration, information and materials flows are generated between them. The main flows take place between "Plant Node Agents". Each node sends orders and receives materials from their suppliers' nodes. At the same time, they receive orders and provide materials to their customer nodes. Information flows to send orders between nodes may have associated delays depending on the dynamic planning of each node.

In Figure 6, we see the UML sequence diagram showing the agents' interaction over time. 


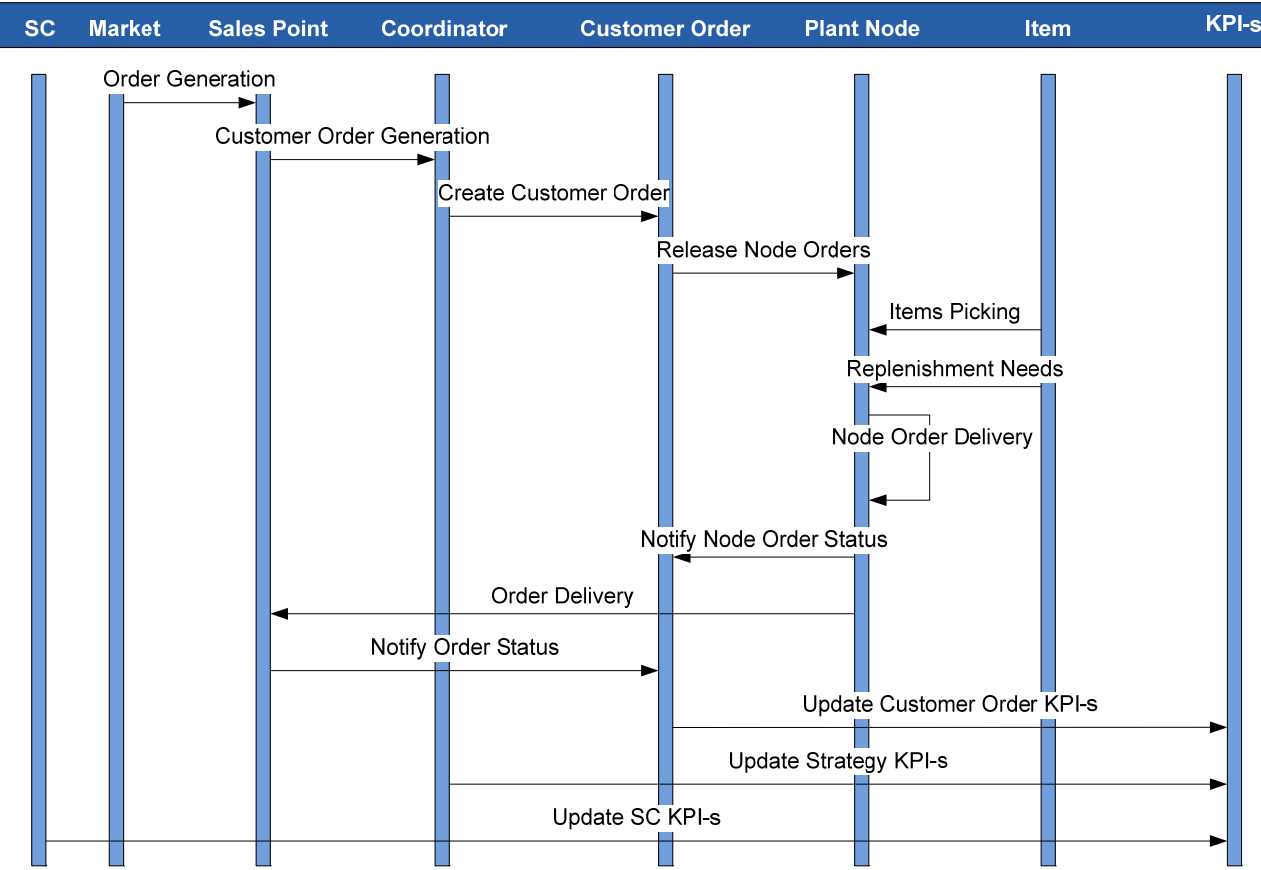

Figure 6: Agents’ interaction chart.

Material flows can have different degrees of complexity depending on the location of origin and destination nodes. In the case studied, these flows are complex taking into account different shipping modes regulated by international commercial terms (INCOTERMS), the different means of transport, exportimport tariffs and rates as well as costs and delivery times.

\section{EXPERIMENTAL DESIGN AND OUTCOMES}

\subsection{Experimental Design Description}

To perform the experiments, it have been considered as input variables (factors) the currency exchange rates and import tariffs for each of the two configurations of the supply network. Tables 1 and 2 show the range of variation of each factor indicating the minimum, current and maximum values as well as the incremental step of the range that determines the number of values (levels) considered for each factor.

Table 1: Factors and levels for Supply Network Configuration 1: Valve assembly in Brazil.

\begin{tabular}{rlllll}
\hline Factors & Min & Current & Max & Step & Levels \\
\hline Exchange rate EUR/BRL & 2,25 & 2,40 & 2,55 & 0,15 & 3 \\
Exchange rate USD/BRL & 1,50 & 1,82 & 1,90 & 0,10 & 4 \\
Brazilian Tariff (valve components) & $12 \%$ & $14 \%$ & $16 \%$ & $2 \%$ & 3 \\
\hline
\end{tabular}

Table 2: Factors and levels for Supply Network Configuration 2: Valve assembly in China.

\begin{tabular}{rlllll}
\hline Factors & Min & Current & Max & Step & Levels \\
\hline Exchange rate EUR/USD & 1,25 & 1,35 & 1,50 & 0,12 & 3 \\
Exchange rate USD/BRL & 1,50 & 1,82 & 1,90 & 0,10 & 4 \\
Brazilian Tariff (finishedvalves) & $16 \%$ & $18 \%$ & $20 \%$ & $2 \%$ & 3 \\
\hline
\end{tabular}

It is important to note that the U.S. Dollar (USD) has been taken as currency for China because commercial transactions inside the supply network are done in that currency. Also, the values corresponding 


\section{Saiz and Uribetxebarria}

to import tariffs in Brazil depending on whether the imported goods are components' valves or finished valves already assembled being higher in the latter case. This is a common formula to protect the country's industry promoting the accomplishment of value-added operations at home.

The experimental method used is a full factorial design of $72(36+36)$ experimental units resulting from combining the levels of the three factors for both supply network configurations. For each of the experimental units, several simulations with the same demand profile have been performed, taking as data for analysis the average value of the product margin generated as output variable.

\subsection{Outcomes}

The analysis of data generated by the experiments simulation has been carried out in two stages:

First, an analysis of variance (ANOVA) has been conducted as a method of contrast to know if a factor by itself or an interaction between factors affect the output variable. The confidence level employee has been $95 \%$ conforms to the level of statistical significance of $5 \%$ that is commonly used for this type of analysis. Tables 3 and 4 shows the ANOVA results for both configurations.

Table 3: ANOVA results for Supply Network Configuration 1: Valve assembly in Brazil.

\begin{tabular}{lccccc}
\hline $\begin{array}{c}\text { Source of } \\
\text { Variation }\end{array}$ & $\begin{array}{c}\text { Degrees of } \\
\text { Freedom }\end{array}$ & $\begin{array}{c}\text { Sum of Squares } \\
\text { [Sequential] }\end{array}$ & $\begin{array}{c}\text { Mean Squares } \\
\text { [Sequential] }\end{array}$ & F Ratio & P Value \\
\hline Model & 23 & 0,0137 & 0,0006 & $1,31 \mathrm{E}+05$ & $4,01 \mathrm{E}-29$ \\
A:EUR/BRL & 2 & 0,0005 & 0,0003 & $5,86 \mathrm{E}+04$ & $1,15 \mathrm{E}-24$ \\
B:USD/BRL & 3 & 0,0124 & 0,0041 & $9,03 \mathrm{E}+05$ & $\mathbf{2 , 2 1 E}-\mathbf{3 2}$ \\
C:Tariff & 2 & 0,0008 & 0,0004 & $9,14 \mathrm{E}+04$ & $8,02 \mathrm{E}-26$ \\
AB & 6 & $1,56 \mathrm{E}-08$ & $2,61 \mathrm{E}-09$ & 0,5714 & $\mathbf{0 , 7 4 6 1}$ \\
AC & 4 & $9,39 \mathrm{E}-08$ & $2,35 \mathrm{E}-08$ & 5,1429 & 0,012 \\
BC & 6 & $2,38 \mathrm{E}-06$ & $3,97 \mathrm{E}-07$ & 86,9286 & $3,48 \mathrm{E}-09$ \\
Residual & 12 & $5,48 \mathrm{E}-08$ & $4,56 \mathrm{E}-09$ & & \\
Total & 35 & 0,0137 & & & \\
\hline
\end{tabular}

Table 4: ANOVA results for Supply Network Configuration 2: Valve assembly in China.

\begin{tabular}{|c|c|c|c|c|c|}
\hline $\begin{array}{l}\text { Source of } \\
\text { Variation }\end{array}$ & $\begin{array}{l}\text { Degrees of } \\
\text { Freedom }\end{array}$ & $\begin{array}{l}\text { Sum of Squares } \\
\text { [Sequential] }\end{array}$ & $\begin{array}{l}\text { Mean Squares } \\
\text { [Sequential] }\end{array}$ & F Ratio & P Value \\
\hline Model & 23 & 0,0925 & 0,004 & $2,74 \mathrm{E}+06$ & $4,74 \mathrm{E}-37$ \\
\hline A:EUR/BRL & 2 & 1,32E-05 & 6,62E-06 & 4514 & $5,47 \mathrm{E}-18$ \\
\hline B:USD/BRL & 3 & 0,0885 & 0,0295 & $2,01 \mathrm{E}+07$ & $1,82 E-40$ \\
\hline C:Tariff & 2 & 0,004 & 0,002 & $1,36 \mathrm{E}+06$ & $7,28 \mathrm{E}-33$ \\
\hline $\mathrm{AB}$ & 6 & 8,80E-08 & 1,47E-08 & 10 & 0,0004 \\
\hline AC & 4 & 5,87E-09 & 1,47E-09 & 1 & 0,4449 \\
\hline BC & 6 & 1,57E-05 & 2,61E-06 & 1782 & 5,55E-17 \\
\hline Residual & 12 & 1,76E-08 & 1,47E-09 & & \\
\hline Total & 35 & 0,0925 & & & \\
\hline
\end{tabular}

Values displayed in the two tables show that, for both configurations, the exchange rate USD/BRL is the factor that most affects the product margin because it has a P Value much smaller than other factors. To a lesser extent, import tariffs is another relevant factor when the valve is assembled in China.

Second, the effect of relevant factors and interactions on the output variables has been analyzed. This can be done by means of effect graphics in which factor values are plotted on the $\mathrm{X}$ axis and product margin percentages on the $\mathrm{Y}$ axis. Solid line shows the results for the valve assembly in Brazil and the dashed line for the valve assembly in China.

Figure 7 shows how the increase in the exchange rate EUR/BRL mainly affects the configuration 1 (valve assembly in Brazil) because more product components are provided from European suppliers 


\section{Saiz and Uribetxebarria}

which operates in Euros. When the valve is assembled in China, this factor does not have influence. It should be emphasized that the product margin is higher when the valves are assembled in Brazil having to increase significantly the exchange rate, well above 2.6, so that the option of assembling in China generate greater product margin.

As indicated above, the exchange rate USD/BRL is the factor that most affects the product margin of the two configurations of the supply network. This can be clearly seen in Figure 8. When the valve is assembled in Brazil, there is a significant reduction in the margin when the exchange rate raises due to components supplied from China (body and cone) are the most expensive of the valve. This reduction is even more pronounced when the valve is assembled in China reaching $15 \%$. For the same increase in the exchange rate USD/BRL, the alternative of assembling in Brazil produces lower margin reduction. Only in the event that the exchange rate is low, the option of assembling in China becomes a possible alternative.

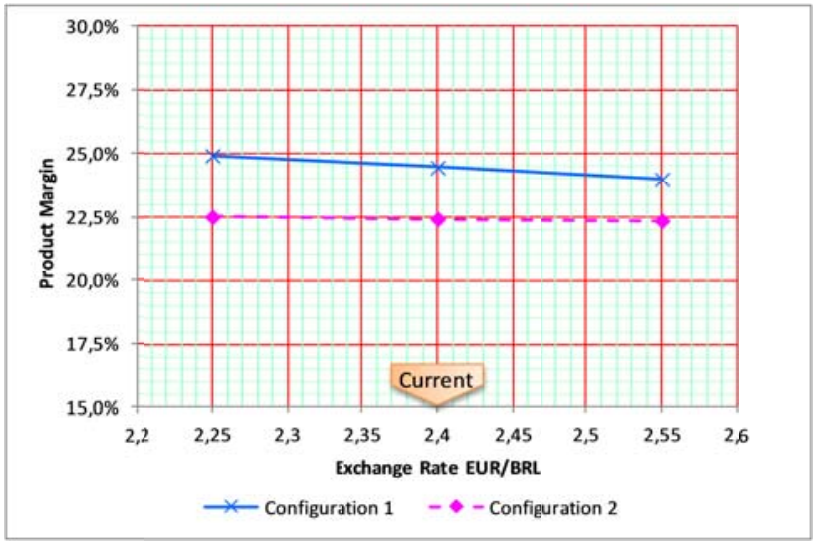

Figure 7: Effect plot of exchange rate EUR/BRL.

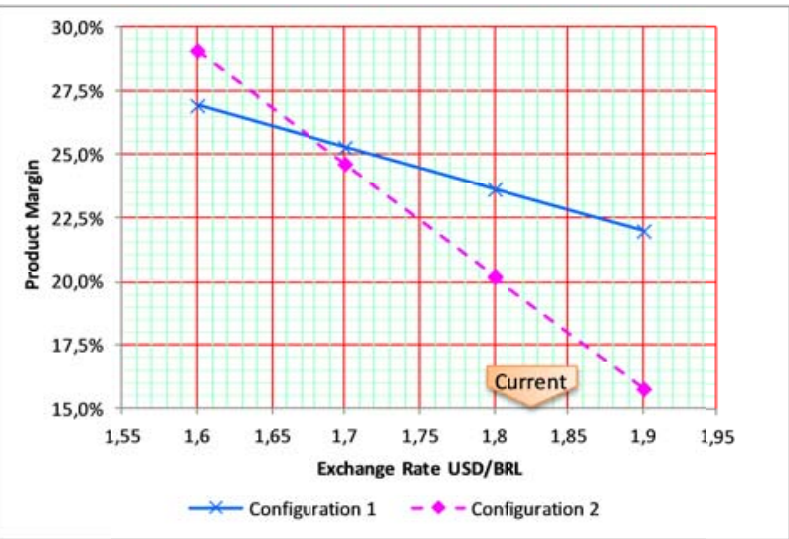

Figure 8: Effect plot of exchange rate USD/BRL.

With respect to the last factor, Figure 9 shows that the effect of import tariffs on the product margin is much more significant when the valves are assembled in China due to higher tariffs on the import of finished products. For a same increase in import tariffs, the reduction in the product margin when the assembly is made in China is more than twice higher compared to assembly in Brazil.

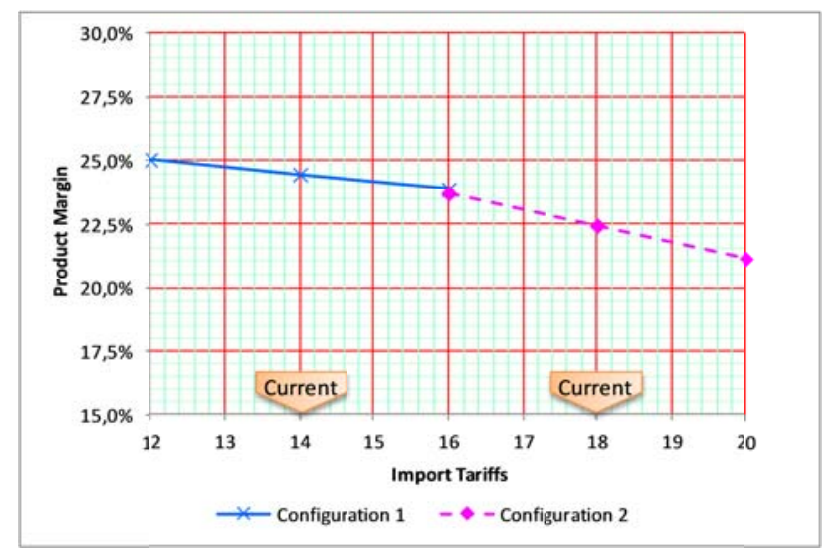

Figure 9: Effect plot of Import Tariffs in Brazil.

Finally, the interactions between factors have been considered concluding that the interaction is minimal and does not influence the experimental results. 


\section{Saiz and Uribetxebarria}

\section{CONCLUSIONS}

From the experimental outcomes, it can be stated that the configuration of the supply network more interesting for the company in the current scenario is to perform the valve assembly in Brazil. This situation could change in the event of there being a strong appreciation of the Brazilian currency against the U.S. Dollar with an exchange rate USD/BRL less than 1.65. In this case, it should be compared the margin improvement generated against the margin reduction caused by the effect of exchange rate EUR/BRL and the resulting higher import tariffs of assembling valves in China. Observing the evolution of economic indicators is not expected a substantial increase in the exchange rate EUR/BRL so this factor is on the side of the Brazilian option. On the contrary, it seems that there is a trend to reduce import tariffs on Brazil which would increase the possibilities of valves assembly in China.

Obviously, for strategic decision making of this kind, the company must take into account other factors such as the evolution of the demand in the Brazilian market and the evolution of the productions costs in each of the countries involves in the supply network. For example, a significant decrease in the Brazilian demand can make that structural costs of the assembly plant in Brazil penalize heavily its profitability because this plant only supplied valves to the Brazilian market. On the contrary, this effect in the Chinese plant is much lower since supplies components to other plants of the supply network of the company and different finished products to other markets.

Case study results have enabled the company to have a new insight into the impact of currency exchange rates and tariffs on how to deliver products in a global competitive scenario. The complexity associated with these strategic decisions make that analysis as performed provide valuable information to decision makers. Combining this analysis with other similar belonging to different scenarios as, for example, variations in demand in specific market regions or products, in logistics costs resulting from changes in energy prices or in production costs of countries involved in the global supply network will allow companies to improve their ability to adapt quickly and efficiently its supply network to each specific market scenario.

As main conclusion of the study, it can be stated that the joint use of simulation and experimental design techniques can make companies more aware of the benefits and risks associated to strategic decision making related to the design of supply networks. By providing a systematic quantitative and objective evaluation of the outcomes resulting from simulating different scenarios of uncertainty enables the identification, assessment and prioritization of main factors affecting the results of the company.

\section{ACKNOWLEDGMENTS}

The research leading to these results has received funding from the European Community's Seventh Framework Programme (FP7/2007-2013) under grant agreement nº NMP2-SL-2009- 229333.

\section{REFERENCES}

Bagchi, S., S. Buckley, M. Ettl, and G. Lin. 1998. "Experience using the IBM supply chain simulator.” In: Proceedings of the 1998 Winter Simulation Conference, Edited by D. J. Medeiros, E. F. Watson, J. S. Carson and M. S. Manivannan, 1387-1394. Piscataway, New Jersey: Institute of Electrical and Electronics Engineers, Inc.

Canel, C., and B. M. Khumawala. 1996. "A mixed-integer programming approach for the international facilities location problem.” International Journal of Operations \& Production Management 16:4968.

Chang, Y., and H. Makatsoris. 2001. "Supply chain modelling using simulation.” International Journal of Simulation 2(1):24-30

Chopra, S., and P. Meindl. 2004. Supply Chain Management: Strategy, Planning and Operations. 2nd ed. Prentice Hall, Upper Saddle River, NJ. 
Cohen, M.A., and H. L. Lee. 1989. "Resource deployment analysis of global manufacturing and distribution networks.” Journal of Manufacturing and Operations Management 2:81-104.

Ferdows, K. 1997. "Making the most of foreign factories.” Harvard Business Review 75:73-88.

Haug, P. 1992. "An international location and production transfer model for high technology multinational enterprises.” International Journal of Production Research 30:559-572.

Integrated Manufacturing Technology Initiative (IMTI). 2000. Modelling and Simulation Roadmap. http://www.imti.net.

Kelton, W. D. 1999. “Designing simulation experiments.” In Proceedings of the 1999 Winter Simulation Conference, Edited by P. A. Farrington, H.B. Nembhard, D.T. Sturrock, and G.W. Evans, 33-38. Institute of Electrical and Electronics Engineers, Piscataway, New Jersey.

Kelton, W. D. 2000. "Experimental Design for Simulation.” In Proceedings of the 2000 Winter Simulation Conference, Edited by J. A. Joines, R. R. Barton, K. Kang, and P. A. Fishwick, 32-38. Piscataway, New Jersey: Institute of Electrical and Electronics Engineers, Inc.

Kleijnen, J.P.C. 1998. "Experimental design for sensitivity analysis, optimization, and validation of simulation models.” In Handbook of simulation, Edited by J. Banks, 173-223. New York: John Wiley.

Lowe, T.J., R. E. Wendell, and G. Hu. 2002. "Screening location strategies to reduce exchange rate risk." European Journal of Operational Research 136:573-590.

MacCormack, A. D., L. J. I. Newmann, and D. B. Rosenfield. 1994. "The new dynamics of global manufacturing site location.” Sloan Management Review 35:69-84.

Meixell, M. J., and V. B. Gargeya. 2005. "Global supply chain design: A literature review and critique.” Transportation Research Part E 41:531-550.

Petrovic, D. 2001. "Simulation of supply chain behaviour and performance in an uncertain environment." International Journal of Production Economics 71:429-438.

Phelps, R. A., D. J. Parsons, and A. J. Siprelle. 2001. "SDI supply chain builder: simulation from atoms to the enterprise.” In: Proceedings of the 2001 Winter Simulation Conference, Edited by B. A. Peters, J. S. Smith, D. J. Medeiros, and M. W. Rohrer, 246-249. Piscataway, New Jersey: Institute of Electrical and Electronics Engineers, Inc.

Ritchie-Dunham, J., D. J. Morrice, J. E. Scott, and E. G. Anderson. 2000. “A strategic supply chain simulation model.” In: Proceedings of the 2000 Winter Simulation Conference, Edited by J. A. Joines, R. R. Barton , K. Kang, and P. A. Fishwick, 1260-1264. Piscataway, New Jersey: Institute of Electrical and Electronics Engineers, Inc.

Saiz E., E. Castellano , J. M. Besga, I. Zugasti, and F. Eizaguirre. 2006. "Global and Flexible Supply Networks Modelling and Simulation". In: Operations and Technology Management II: Complexity Management in Supply Chains. Concepts, Tools and Methods, Edited by T. Blecker, and W. Kersten W, Series on Operations and Technology Management 2: 161-188. Berlin: Erich Schmidt Verlag.

Siprelle, A. J., D. Parsons, and R. A. Phelps. 1999. "SDI Industry Pro: simulation for enterprise wide problem solving." In: Proceedings of the 1999 Winter Simulation Conference, Edited by P. A. Farrington, H. B. Nembhard, D. T. Sturrock, and G. W. Evans, 241-248. Piscataway, New Jersey: Institute of Electrical and Electronics Engineers, Inc.

Swain, J. J., and P. A. Farrington. 1994. "Designing simulation experiments for evaluating manufacturing systems." In Proceedings of the 1994 Winter Simulation Conference, Edited by J. D. Tew, M. S. Manivannan, D. A. Sadowski, and A. F. Seila, 69-76. Piscataway, New Jersey: Institute of Electrical and Electronics Engineers, Inc.

Vidal, C.J., and M. Goetschalckx. 2001. "A global supply chain model with transfer pricing and transportation cost allocation.” European Journal of Operational Research 129:134-158.

Yin, R. 1994. Case study research: Design and methods. 2nd ed. Beverly Hills, CA: Sage Publishing.

Zhang, J., I. Hunt, and C. O’Connor. 1998. "Simulating and modeling supply chain activities in the food industry.” http://www.cimru.nuigalway.ie. 


\section{AUTHOR BIOGRAPHIES}

EDUARDO SAIZ has a degree in Industrial Engineering by ETSII Bilbao in the specialty of Industrial Organization (1984). In 1995 obtained the CPIM certificate in Management of Production and Inventory awarded by APICS (American Production and Inventory Control Society). From 1986 he has been working in the Technology Research Center IK4-Ikerlan in the knowledge area of Design and Production Technologies leading and participating in several R \& D projects for the European Union and the Spanish and Basque Governments as well as in transfer projects to companies. His main research interests are related to the design and implementation of production management models, planning systems, supply chain management and logistics with a focus on customized product. Since 2007, he is reviewer of innovation projects proposals for the Basque Government. His email address is esaiz@ikerlan.es.

JONE URIBETXEBARRIA is Matrise of computing by the University Paul Sabatier in Toulouse (1993) and holds a graduate diploma in the specialty of robotics (DESS in IRR) (1994). In 2000 obtains a Master in Production Management at the University of Mondragon. In 1995 he began working in the Technology Research Center IK4-Ikerlan in the knowledge area of Robotics. Since 1999 he is working in the area of Design and Production Technologies. His main research interests are related to the product definition and design (functional design, modular design and configuration) and supply network management and simulation in mass customization scenarios. His email address is juribetxebarria@ikerlan.es. 